\title{
Exploration and Practice of '4441' Diamond Talents Training Model of Electrical Information
}

\author{
Shu-Bin Yang*, Xiao-Ling Wen, Yuan-Feng Huang \\ School of Electrical and Information, Wuhan Institute of Technology, Wuhan, China \\ Email address: \\ yshubin@wit.edu.cn (Shu-Bin Yang), whwxl_2004@163.com (Xiao-Ling Wen), hyf668899@163.com (Yuan-Feng Huang) \\ ${ }^{*}$ Corresponding author
}

\section{To cite this article:}

Shu-Bin Yang, Xiao-Ling Wen, Yuan-Feng Huang. Exploration and Practice of '4441' Diamond Talents Training Model of Electrical Information. Education Journal. Vol. 6, No. 6, 2017, pp. 170-176. doi: 10.11648/j.edu.20170606.12

Received: September 30, 2017; Accepted: November 7, 2017; Published: November 21, 2017

\begin{abstract}
Intelligent information twenty-first Century needs a great number of electric information engineers and technical personnel with engineering practice and innovation ability. On the basis of CDIO, PBL and accreditation of engineering education theory, the training target is determined according to the information age talent demand. To change the teaching idea as the foundation, construct the teaching system for content, reform the teaching methods, means of engineering experiment as an example, exploration and research theme clues are carried out. After 3 years practice, from the aspects of training objectives, theoretical foundation, teaching contents and methods to implement the integration of personnel training, to achieve the goal of cultivating engineering talents, the dilemma of difficult employment and talent shortage is effectively solved and good results were obtained.
\end{abstract}

Keywords: Talents Training Model, Four Combination Teaching Methods, Distributed Teaching, Teaching System, Teaching Empirical Research

\section{Introduction}

Intelligent information twenty-first Century needs a great number of engineering practice ability and innovation ability of electric information engineering and technical personnel, cultivating perfect personality and professional knowledge structure and engineering practice ability, innovative consciousness and team spirit of innovative talents is imperative [1]. The theory and practice of domestic and external engineering personnel training to do a lot of research, such as Europe and the United States established the certification organization of European engineering education network (ENAEE), the Accreditation Board for engineering and Technology (ABET), China's Ministry of education, Ministry of Finance issued a document pointed out that the cultivation of applied innovative talents is the inevitable social economy the development is a basic policy of the party and state personnel training. Therefore, there has been a consensus on the cultivation of innovative engineering talents at home and abroad, but there are still some problems in how to effectively implement qualified personnel $[2,3]$. One is the teachers and students in engineering teaching the concept of curing is not solid, change of thought into action in actual teaching is not enough; the two is the existing teaching system is not adapt to or not to support engineering education and training goals, professional basic theory can force in engineering practice has not been weakened, the trend is strengthening; three teaching now the implementation of the teaching process although have, but a mere formality, the implementation is not enough, can not provide training methods suitable for the engineering innovative talents, but also did not consider the number of students increased from teaching resources shortage, leading to the existence of students "difficult employment" and the employer talent shortage dilemma dilemma.

The "4441" training mode is designed on the basis of Engineering Education in CDIO, PBL and Accreditation of engineering education theory, from the social demand analysis of the talent training target is determined from the concept, basis, teaching contents, training means training all-round realization of the integration of the information age of electrical information engineering innovative talents, better to solve the above problems. 


\section{Reform Content of Talent Training Mode}

"4441" mode on how to cultivate talent two major basic problems of cultivating talents, what reform from the training target, to change teaching concept, teaching content, teaching methods and construction combined with empirical clues to carry out exploration and research.

\subsection{Theoretical Study and Analysis of the Status to Determine Goals}

Study at home and abroad to strengthen the cultivation of innovation ability theory engineering talent, especially the theory of CDIO, PBL and Engineering Education Accreditation of engineering education as the core, combined with extensive research to determine the information age of electric information talents training target for engineering innovative talents of professional knowledge structure and engineering practice ability, innovative awareness and team spirit.

\subsection{Four Transformation of Teaching Philosophy to Tamp the Foundation}

After entering the twenty-first Century, the development of information technology has brought new vitality to the traditional industries which are weak in innovation. In particular, the recent industry 4.0 has injected new vitality and new meaning into the development of various industries, and will promote the traditional industries to enter the era of intelligent information. In the process of social and economic development, a large number of engineering and technical talents with engineering practice ability and innovative ability are needed. In order to meet the demand for talents in the new situation, our country's higher education has been transferred from elite education to popular education, and it is gradually developing from "specialist education" to "special generalist education". Therefore, to cultivate healthy personality, professional knowledge structure and engineering practice ability, innovative consciousness and team spirit in the complex, innovative electric information talents is imperative, which requires further update the educational concept. Thus, the four changes of the teaching idea based on "three turns one system" (small class, engineering, individualized and tutorial system) have been established[4-6]. One is the teaching of Teacher centered student-centered, which makes the whole teaching one-sided emphasis on teachers and teaching materials for the role of student centered activities that stimulate students enthusiasm heart to learn, to improve learning initiative and efficiency; two is a single professional as the core of education to college generalist categories of professional and general education combined with the integration of education, the cultivation of talents is not only the professional knowledge and ability of the so-called professionals, but as the solid foundation, caliber generous and rich innovation consciousness and team work in electrical and information engineering innovative talents ability; three is to change in the classroom teaching to combine multi class, multi class teaching idea of constructing "Fusion Engineering Talent four classroom interactive fusion extension" culture; four is a single class Change the teaching organizational form of teaching organization form to the class and the tutor system with the breaking of original class teaching idea, construct multi-level and multi time can be changed flexibly distributed to tutor system based on flexible classes teaching form, to achieve personalized individualized education. By four to change the concept of teaching, can stimulate teachers' and students' thinking and initiative, professional and lay a solid theoretical foundation, broaden the students, improve students' learning ability, practice ability, engineering ability, innovation ability, communication skills, ability to adapt, improve students' comprehensive quality and team spirit, to cultivate students has a strong sense of social responsibility and sense of mission, to adapt to contemporary economic and social development of science and technology, need solid theoretical basis, practical ability and high comprehensive quality and innovative spirit of the electric information of advanced engineering and technical personnel, so as to develop a solid foundation for the realization of target solid talent.

\subsection{Four Level Teaching System Construction to Solid Content}

Building and implementing innovative curriculum system is the ultimate way to achieve the goal of personnel training [7-9]. Electric information engineering talent to follow the "thick foundation, wide caliber, ability, innovation" philosophy of education, establish training objectives to lay a solid foundation, to broaden the knowledge and ability, improve the quality of the talents, adhere to the set oriented engineering oriented, project driven means, knowledge and ability training, and the practice of teaching, and teaching the theory of professional education and comprehensive quality education of the unity of thinking of cultivating talents in engineering education, with $\mathrm{CDIO}, \mathrm{PBL}$ and engineering education certification of the results of the theory and practice as the foundation, the foundation of "professional education, basic education, professional education, comprehensive quality education on the four levels of parallel financing with the progressive fusion network structure course system and experiment and practice, design and innovation" four levels of progressive deepening of practice teaching system. Based on the general public to build basic education platform, innovative education for different majors, different types and different personality characteristics of college students to carry out multi-level and diversified professional education and engineering and comprehensive quality, improve the quality of personnel training.

The curriculum system of the whole training program adopts vertical and horizontal interweaving and network course layout to increase the depth and breadth. In the longitudinal axis, through theoretical study and practical 
training in different stages, different levels of the basic courses, professional basic courses, professional core courses and direction together, the students are no longer after a lost one, but all through the training project, so that by the development ladder in the transverse direction; the space axis, breaking the various professional restrictions, modularized curriculum implementation of categories of electrical information, so that the students can choose according to the flexible and practical arrangements corresponding professional knowledge training project to study. At the same time, based on "professional education, basic education, professional education, comprehensive quality education curriculum system based on the four level, create corresponding" project type, suitable for the cultivation of innovative talents progressive deep type four level practice teaching system and curriculum module.

\subsection{Four Combination Teaching Methods to Prominent Means}

In order to realize the training target of electrical information talents, and to improve the quality of personnel training, the reform of teaching methods of "Four Combinations" has been created and carried out [10-12].

\subsubsection{Teaching and Learning Closely Integrated to Improve Teaching Effect and Students' Ability}

In order to realize the effective combination of good teaching and good learning, teachers should be led and students should be the main part, so as to arouse the enthusiasm of students' learning and cultivate their independent learning ability. Construction of Pyramid teach teaching team closely and learning, the teaching team composed of school teachers and enterprise engineers, formed the outstanding senior students to participate in the work of teaching mode construction based on students, young teachers and engineers as the backbone, professors and senior engineers for the spire of the teaching team. Guide the students to team mutual learning, the low grade students in high grade students as the teaching methods of teachers, to improve students qualities and training of low grade students practical ability to. The reform of teaching methods, teaching means and methods to implement the "interactive, heuristic and research teaching" + "E-Learning", the implementation of the comprehensive reform of the curriculum, teaching methods change the teacher centered "base", "the application and practice of interactive, heuristic and research teaching method and based on the information technology teaching methods, teachers play a leading role and students, guide students to self-study, fully mobilize the enthusiasm of the students. The reform of assessment methods, explore the evaluation model of students and the quality of teachers' examination and examination method, the implementation of open test, the whole process of design, project development system or device fabrication, debugging and document programming, writing into the exam, to achieve" fusion of knowledge, test level, to test and promote science, to test and promote teaching purpose.

\subsubsection{Learning and Doing Closely Integrated to Solve Practical Problems}

The construction of electric information consciousness based education platform through professional, and the electricity basic course practice to optimize the combination of different majors, different types and different personality characteristics of college students curriculum module. And the original scattered professional curriculum design, optimize the combination of professional integrated curriculum design, and additional enterprises in the units of the project comprehensive training content. With the combination of "tutor system" and "project driven", we should train students' practical practical ability and engineering application ability and innovative ability by relying on the four level experimental teaching system.

\subsubsection{Resources Inside and Outside Campus Closely Integrated to Improve Students' Engineering Application and Innovation Ability}

The construction of "four classroom interactive fusion extension system, engineering talent education practice the first class $[13,14]$ : do the experiment classroom teaching and classroom building, challenging learning class, improve the academic challenge and student teacher interaction; second class: efforts to build the hospital" creativity, innovation and entrepreneurship three innovation center, the institute has established a center of innovation and innovative studio, organize and participate in various science and technology competitions (competition); third class: the construction of off campus practice base, the implementation of school enterprise joint training, strengthen cooperation, focus on the construction of practice base and employment base and make full use of talents, promote the joint education of school and enterprise, the ability of engineering practice; fourth class: normal and summer open laboratory, into the teacher's scientific research laboratory, including out of the country, to participate in the study plan and short-term learning, improve the international perspective Etc..

\subsubsection{Independent Management and Collective Team Activities Closely Integrated to Improve the Overall Quality}

In twenty-first Century put forward higher requirements on talents training in Colleges and universities, not only individuals with profound knowledge, strong practical ability and the ability to work independently, but also have strong team spirit, combine the individual and team development. In view of the current student management and quality education, the implementation of self management as the core of student management system, and into the students' learning and life process of quality education system. The class of "self management, democratic management, humanization management + team" student work mechanism construction, to improve the students' ability of self management, let the democratic election, democratic appraisal, regular assessment, team learning has become the work characteristics, realize the effective interaction between students, teachers and students, let the students show in full 
individuality and personal ability at the same time, increase the team activities of the organization, through the formation and maintenance of virtual team, team, cross course team and the team, to achieve self management and team based learning. In order to strengthen the training of students' cooperative spirit and sense of responsibility, the overall concept and service consciousness, enhance the team cohesion function, incentive function, guiding function and control function so as to realize the comprehensive understanding, improve students' Ideological and moral quality, cultural quality, psychological quality, science and technology quality and team spirit, effective to solve the current college students self-control ability and team cooperation ability is not strong, comprehensive quality not high enough.

\subsubsection{Teaching Practice in Engineering Experimental Class to Strengthen Empirical Analysis}

In May 2012, an experimental class of engineering was set up to carry out empirical research. After sufficient investigation and discussion, a project report and program were formed, and organizational structure was established in September of the same year. In May 2013, 33 students were enrolled in the experimental class with voluntary enrollment, and the "4441" training mode was implemented. Individualized development of three year project training plan and implementation plan, the application of distributed teaching method. Low grade stage, to focus on learning and training, guiding, learning theory and basic training; high grade stage, with the guidance of tutors, with the subject of cooperation with enterprises to carry out teaching; at the beginning of each semester learning forum, semester academic meeting at the end of the semester, works on display and summarize and exchange. After the 3 years, 33 students ( 1 dropouts) good results were obtained, 14 students enrolled in the study of 985 college students, $43.75 \%$ postgraduate enrollment rate, employment rate of $100 \%$, to obtain patents and published papers (articles), a number of provincial and ministerial level subject contest award 12, Hubei Province outstanding bachelor's degree thesis in 2016 accounted for $27.27 \%$ of the hospital. The above shows that the "4441" training model has been proved to be successful and can be popularized and applied. It is imperative to develop engineering talents with sound personality, professional knowledge, reasonable structure, strong engineering practice ability, innovative consciousness and team spirit. The theory and practice of domestic and external engineering personnel training to do a lot of research, such as Europe and the United States established the certification organization of European engineering education network (ENAEE), the Accreditation Board for engineering and Technology (ABET), China's Ministry of education, Ministry of Finance issued a document pointed out that the cultivation of applied innovative talents is the inevitable social economy the development is a basic policy of the party and state personnel training. Therefore, there has been a consensus on the cultivation of innovative engineering talents at home and abroad, but there are still some problems in how to effectively implement qualified personnel. One is the teachers and students in engineering teaching the concept of curing is not solid, change of thought into action in actual teaching is not enough; the two is the existing teaching system is not adapt to or not to support engineering education and training goals, professional basic theory can force in engineering practice has not been weakened, the trend is strengthening; three teaching now the implementation of the teaching process although have, but a mere formality, the implementation is not enough, can not provide training methods suitable for the engineering innovative talents, but also did not consider the number of students increased from teaching resources shortage, leading to the existence of students "difficult employment" and the employer talent shortage dilemma dilemma.

\section{Innovation of Talent Training Mode Reform}

\subsection{Training Mode Innovation -- "4441" Integrated Talents Training Mode Based on Demand Oriented}

On the basis of Engineering Education in CDIO, PBL and Accreditation of engineering education theory, based on the information age of electrical information demand determine the training objectives, in order to achieve the teaching idea 4 transformation based teaching system, the 4 level construction contents and teaching methods of combination of 4 means of the reform of engineering, experimental classes to carry out 1 kinds of teaching empirical study feedback, a cultivation mode of electric information of the "4441" diamond type integration as shown in Figure 1.

\subsection{Formula Innovation of Teaching System -- Four Level Teaching System of Time and Space Based on CDIO and $P B L$}

In engineering oriented, project driven method, CDIO, PBL and engineering education certification theory and practice as the foundation, build the foundation of education, professional basic education, professional education, comprehensive quality education space facility in the four levels of parallel progressive curriculum system and experimental design, innovation, practice, four levels deep practice teaching system. The teaching system adopts vertical and horizontal interweaving and network course layout to increase the depth and breadth. The longitudinal axis, through the training of different levels and stages of theory study and project system the basic courses, professional basic courses, professional core courses and direction are linked together closely, the development ladder, increasing the depth of learning; the two axes, break professional restrictions, curriculum modularization and plane according to the training project, flexible selection, increase the breadth. 


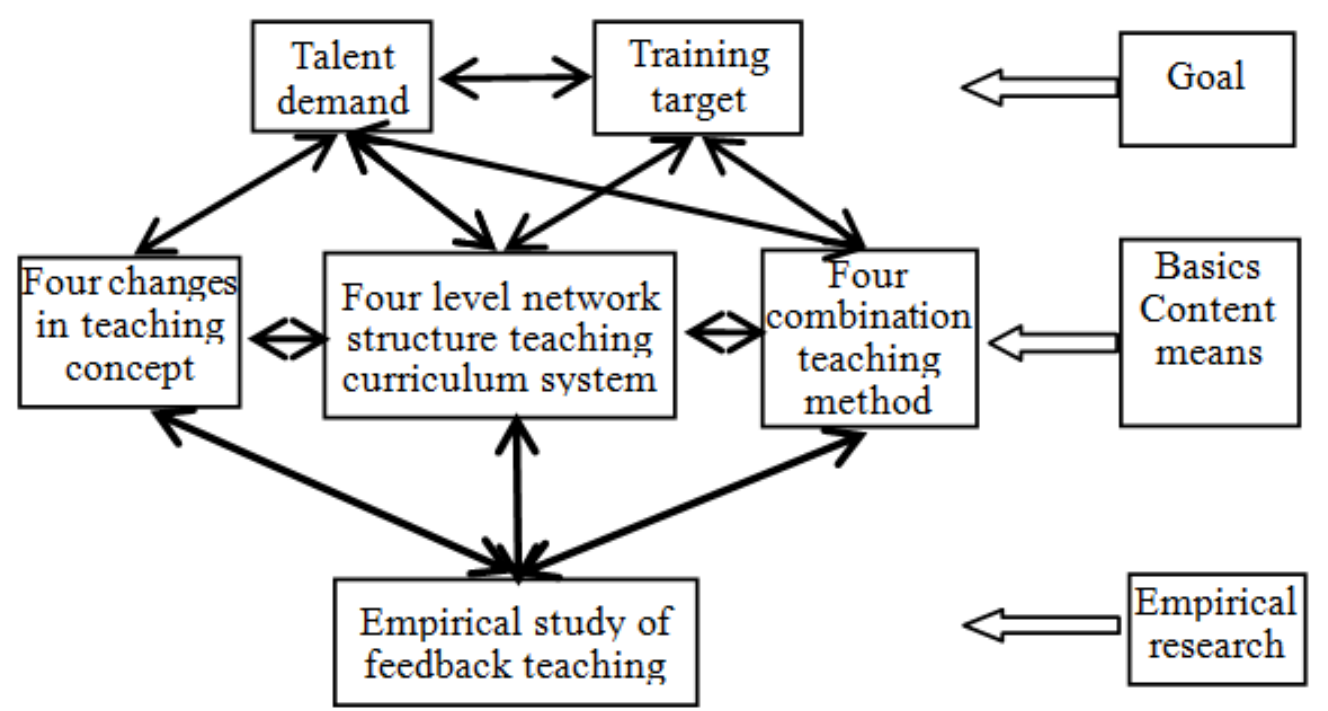

Figure 1. Sketch map of "4441" Diamond talents training mode.

\subsection{Innovation of Teaching Methods -- Distributed Teaching Method Based on the Four Combination}

The implementation of teaching reform of the teaching method of four closely combined with the learning, learning and doing more, inside and outside the classroom and students autonomous management team and the collective activities of the organization, to achieve the innovation of distributed teaching method based on the combination of four, i.e. parallel class theory teaching (concentration), flexible structure (the small flexible number (3-30 people)) to carry out practice teaching and decentralized training in engineering practice (dispersion) of the distributed teaching method. Flexible classes distributed this kind of teaching method and parallel teaching harmony, can fully utilize and conserve resources, solve the reality of teachers, teaching equipment, teaching time and space problem of teaching resource, which can lay a solid theoretical foundation of the system, but also can make full use of teaching resources to implement individualized education and training.

\section{Application Results of Teaching Reform}

\subsection{Promote Professional Construction}

In the promotion of the original school brand specialty and cultivate professional basis, directly promoted the construction of the quality of the project in 2014, and the rest of the school school approved teaching demonstration center of national chemical engineering practice; 2014 approved for measurement and control technology and instrument specialty in Colleges of Hubei province strategic emerging (pillar) project of culture industry talent, 2016 approved for automation specialty in ordinary universities of Hubei province "the outstanding talents" cooperative education plan "the excellent engineers"; in 2015 to declare the new professional approved information engineering and enrollment. At the same time, it promoted the work of professional project accreditation and audit evaluation, and promoted the construction of professional and quality engineering projects.

\subsection{Promote Curriculum Construction}

The application of CDIO and PBL of the four space facility level teaching system based on the results of training plan amendments to improve the electrical information of 5 professional enrollment training, approved at the provincial level excellent resource sharing course, the comprehensive reform of university class 6 door and nearly 20 door course examination reform; the completion of the docking and joint training of the United States of Indiana State University, the University of Portsmouth and the development of the program, protocol of the co culture exchange; 163 completed the revision of the syllabus, and a clear correlation with the support of 11 projects the ability of each course and ABET is put forward; promote the construction of the course content, provide a guarantee for the realization of engineering education target.

\subsection{Promote Teaching Staff Construction}

The results of the application to promote learning and enhance the teaching concept, teaching method, service level of the teachers, improve the young teachers' teaching level, teaching competition of young teachers for 6 consecutive years won the first prize, the four session of the provincial tournament, winning three consecutive three and won the two prize, and was the first school of micro first class competition. At the same time, more teachers have been selected to practice in the enterprises, and more than 10 experts from outside school have been employed as practical part-time teachers to strengthen the training of "Dual Teacher" teachers. 


\subsection{Promote the Construction of off Campus Practice and Training Bases}

The project driver is the propeller of the theoretical study in the course of training. In addition to the tutor's own research projects, through the combination of school and enterprise, the actual project is an important source of student training projects. Through the construction of $\mathrm{R} \& \mathrm{D}$ bases with the outside campus, the training of engineering innovative talents and the transformation of scientific and technological achievements, 5 new innovative training bases have been created.

\subsection{Improve the Quality of Personnel Training}

After six years' exploration and practice of "4441" Diamond talents training mode of electrical information, we have got the demonstration of engineering experimental class. 33 students volunteered by 10 instructors for guidance, using "4441" mode to carry out training, 33 students ( 1 to take the initiative to withdraw from the good results achieved) training, 14 students enrolled in the study in 985 universities of Shanghai Jiao Tong University, Huazhong University of Science and Technology graduate, postgraduate enrollment rate reached $43.75 \%$ (an average of $19.91 \%$ ), the employment rate of $100 \%$, to obtain patents and published a number of (articles), won the provincial and ministerial level subject contest award 12. Graduates generally enjoy better development and are welcomed and praised by employers and graduate students both at home and abroad.

\subsection{Played a Good Exemplary Role}

Do the reports and preach results in the Changjiang Daily newsletter, ESSE2016, ICEMCT2014, teaching media and the international education conference, Hubei University, Hubei University of Technology and the training mode of Donghua Polytechnic University outside the province more of the colleges use results, provide a reference and a good role model for the relevant professional personnel training. By the students, parents, peer wide concern and praise, effectively meet the needs of the community for talent.

\section{Conclusion}

On the basis of Engineering Education in CDIO, PBL and Accreditation of engineering education theory, from the information age of electric information demand of the talent training target is determined, to change the teaching idea as the foundation, constructs the teaching system for content, reform the teaching methods as a means to carry out empirical research on project of the experimental class theme clues to explore and research. Based on the "three system" teaching philosophy 4 changes, constructing 4 level parallel teaching system, the progressive network curriculum system and practice of progressive in-depth reform of the teaching method of the combination of the 4 , and to the engineering experimental class as the object to carry out 1 kinds of feedback type empirical research, the formation of training mode electric information
"4441" diamond type integration talent, attention and praise mode reform by students, parents, peers and the community to cultivate teaching talents, effectively meet the social demand for talent.

\section{Acknowledgements}

This research was financially supported by the Teaching Research Foundation of the Higher Education Institutions of Hubei Province, China (Grant No. 2014301).

\section{References}

[1] Zhao Shuang, Zhou Wenjun. Study on the employment status and Countermeasures of electrical information undergraduates in local universities [J]. Journal of Changchun University of Technology (research edition of Higher Education), 2015, 36 (1): $78-80$.

[2] Huang Rongjie, Li Genquan, Song Jinfan, Wang Zhipeng. Exploration and practice of "Line Engineer" talent training mode for electrical information specialty in local universities [J]. Journal of Nanyang Normal University, 2012, 12 (11): 91-94.

[3] Ding Yue, Zhang Guoyun, Li Hongmin, et al. Research and exploration of engineering applied talents training for electronic information specialty [J]. Laboratory science, 2016, 19 (1): 236-241.

[4] Chen Xi. Exploration of the training of electric information talents and seamless links of enterprises [J]. Science and Technology Pioneering monthly, 2014 (3): 72-74.

[5] Li Chunhua, Wang Yongliang, He Wei. Exploration of improving college students' practical and innovative abilities [J]. Vocational education forum. 2011 (17): 79-80.

[6] Luo Wenguang, Chen Wenhui, $\mathrm{Hu}$ Bo, et al. Construction of diversified practice teaching mode of electrical information specialty $[\mathrm{J}]$. The research and exploration of laboratory, 2013, 32 (05): 137-141.

[7] Jiang Wenbo, Yang Qiuli, dragon Jun, et al. Reform and exploration of practical teaching system of applied undergraduate course of electronic information [J]. Information technology education in china. 2014 (10): 29-30.

[8] Zhou Wei, Zhang Xiaoxia, Pang Yanrong, Yang Liying, Dong Xiaoping. The whole process of undergraduate tutorial system practice and innovation personnel training $[\mathrm{J}]$. Guangzhou chemical industry. 2016 (12): 25-28.

[9] Luo Guoji, Zhou Mindan, Wang Yingna. Review of undergraduate tutorial system in Colleges and universities in recent years [J]. Journal of East China Institute of Technology (SOCIAL SCIENCE EDITION). 2007 (04): 61-64.

[10] Wang Hai, Wang Zhongmin. Training computer engineering talents with school enterprise cooperation education mechanism [J]. Computer education. 2011 (3): 9-12

[11] Zhang Qinglan, Yang Yang. An analysis of undergraduate tutorial system -- a case study of Y University's Z Laboratory for a number of outstanding undergraduate students [J]. Journal of Yangtze University (SOCIAL SCIENCE EDITION). 2014 (05): 41-44 
[12] Chen Sen, Zhang Shiping, Wu Ping. Exploration and Practice on the research and practice of experimental teaching mode based on topic type $[\mathrm{J}]$. laboratory research and exploration. 2013 (07): 35-37.

[13] Wang Qiong, Sheng Dece, Chen Xuemei. Project driven education [J]. experimental technology and management. 2013 (06): $46-49$
[14] Wang Minghua, Wang Xinlin, Deng Xianjun. Research on the cultivation mode of electronic and communication engineering excellence based on tutorial system and small class $[\mathrm{J}]$. teachers. 2016 (17): 26-29. 